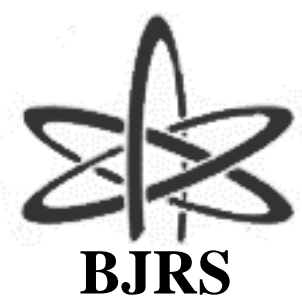
BRAZILIAN JOURNAL $\mathrm{OF}$ RADIATION SCIENCES
07-02A (2019) 01-09

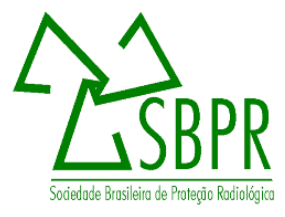

\title{
Seaweed as a source of essential elements
}

\author{
C. R. Albuquerque ${ }^{\text {a. }}$ V. A. Maihara ${ }^{\text {a }}$ C. B. L. Alves ${ }^{\text {a }}$ P. S. C. Silva ${ }^{a}$ \\ ${ }^{a}$ Instituto de Pesquisas Energéticas e Nucleares, Centro do Reator de Pesquisas /Laboratório de Análise por Ativação \\ Neutrônica, Av. Professor Lineu Prestes 224205508-000, São Paulo-SP, Brasil \\ calbuuquerque@gmail.com
}

\begin{abstract}
Overtime seaweed species have been used as a food, mainly due to their high nutritional value. This type of food is considered as a functional food and it contributes to the nutritional human requirements, being beneficial to human health. In this study 13 edible seaweed samples acquired in São Paulo city markets were analyzed and the concentrations of $\mathrm{Cl}, \mathrm{K}, \mathrm{Mg}, \mathrm{Mn}$ and $\mathrm{Na}$ were determined by Instrumental Neutron Activation Analysis (INAA). The following edible seaweed species were analyzed: Nori (Porphyra umbilicates); Hijiki (Hijikia fusiforme); Kombu (Laminaria sp.) and Wakame (Undaria pinnatifida) from China, USA, Japan and South Korea. Undaria pinnatifida species presented the highest $\mathrm{Na}$ concentration and the lowest $\mathrm{K}$ level. The highest concentration variation was obtained for Mn in the Porphyra umbilicates species.
\end{abstract}

Keywords: seaweed, essential elements, activation analysis. 


\section{INTRODUCTION}

Marine algae or seaweeds are autotrophic and photosynthetic organisms that differ from plants and may be unicellular or multicellular [1]. They are also the basis of the food chain for many systems, serving as food for zooplankton, which are heterotrophic microorganisms present in plankton, and are staple foods for larger organisms. Thus these algae play a key role in maintaining life on the planet. They are excellent sources of minerals because of the ability to absorb these inorganic substances from the environment and store them in their systems and they can be used as biological indicators in many studies [2, 3].

In Asian countries algae have been used for centuries as ingredients in soups and salads as lowcalorie foods, while in Western countries their use has traditionally been limited to industrial use as a raw material for extracting alginates from brown algae such as agar-agar and red algae carrageenan [4]. These polysaccharides have been widely used by the food industry as texture modifiers because of their high viscosity and gelling properties [5].

Nowadays the use in Western countries is not limited to industrial use, as the influence of oriental culture in the world has increased considerably overtime, especially in cooking. In recent years algae consumption has increased due to its characteristics as a functional ingredient for formulating healthy foods, aiding in vegan diets to improve nutrition. The production of meat containing seaweed opens new perspectives for the use of these algae [2].

Studies have been carried out to verify the efficacy of algae in alternative treatments of various diseases, such as cardiovascular diseases due to their antioxidant properties [6,7]. It is known that marine algae contain vitamins, minerals and, in particular, have high concentrations of long-chain polyunsaturated omega-3s, which reduces the risk of atherosclerosis and inflammatory heart disease [4].

Essential elements are nutrients recognized as fundamental to the functions of the human body and are traditionally divided into macro minerals and micro minerals or trace elements. Macro minerals are required for the human organism in large quantities while micro minerals or trace elements are needed for the human organism in minor amounts [8]. In this study four species of edible seaweeds commercialized in São Paulo City were analyzed: Hijiki (Hijikia fusiforme), 
Kombu (Laminaria sp). Nori (Porphyra umbilicate) and Wakame (Undaria pinnatifida) and the concentrations of the elements $\mathrm{Cl}, \mathrm{K}, \mathrm{Mg}, \mathrm{Mn}$ and $\mathrm{Na}$ were determined using Instrumental Neutron Activation Analysis (INAA). This technique is important in food research providing reliable results for a number of elements that have great nutritional importance [9].

\section{MATERIALS AND METHODS}

\subsection{Sample Preparation}

Thirteen samples from four species of edible seaweeds commercially available to consumers were purchased from super markets all around São Paulo City. The samples were ground and homogenized using a household mixer, fitted with titanium blades, until they acquire a powder consistency. Table 1 shows the different species of seaweed and its origins.

Table 1: Different species of seaweed and its origins

\begin{tabular}{lc}
\hline Edible seaweed specie & Origin \\
\hline Porphyra umbilicates (Nori) & China \\
Porphyra umbilicates (Nori) & Korea \\
Porphyra umbilicates (Nori) & Japan \\
Porphyra umbilicates (Nori) & U.S.A. \\
Hijikia fusiforme (Hijiki) & Japan \\
Hijikia fusiforme (Hijiki) & China \\
Hijikia fusiforme (Hijiki) & Korea \\
Undaria pinnatifida (Wakame) & China \\
Undaria pinnatifida (Wakame) & Korea \\
Undaria pinnatifida (Wakame) & Japan \\
Laminaria $s p$ (Kombu) & Korea \\
Laminaria $s p$ (Kombu) & Japan \\
Laminaria $s p$ (Kombu) & China \\
\hline
\end{tabular}




\subsection{Instrumental Neutron Activation Analysis (INAA)}

For the $\mathrm{Cl}, \mathrm{K}, \mathrm{Mg}, \mathrm{Mn}$ and $\mathrm{Na}$ determination by INAA about $0.1 \mathrm{~g}$ of the seaweed samples were irradiated for 20 seconds in a thermal neutron flux of $1.0 \times 10^{12} \mathrm{~cm}^{-2} \mathrm{~s}^{-1}$ in a pneumatic station of the nuclear research reactor IEA-R1 at IPEN - CNEN/SP. Cl, K, Mg, Mn and $\mathrm{Na}$ standards and a biological certified reference material were simultaneously irradiated with the samples for standardization and quality control purposes.

Gamma ray measurements were performed using a GC2018 Canberra HPGe detector coupled to a Canberra DSA-1000 multichannel analyzer. Gamma ray spectra were collected and processed using a Canberra Genie 2000 version 3.1 spectroscopy software. Element content calculations were carried out using a Microsoft Excel spreadsheet.

\section{RESULTS AND DISCUSSION}

\subsection{Quality control}

The analytical quality of the results for the technique used (INAA) was checked for the accuracy and precision of the experimental values obtained for the reference material Mixed Polish Herb (MPH) from the Institute of Nuclear Chemistry and Technology- (INCT- Poland). The results showed relative errors (RE) less than $20 \%$ and relative standard deviations (RSD) below $10 \%$ as presented in Table 2. 
Table 2: Concentrations of elements in the Certified Reference Material

\begin{tabular}{ccccc}
\hline Elements & \multicolumn{3}{c}{ INCT-MPH-2 (Mixed Polish Herb) } \\
\hline & $\mathbf{x} \pm \mathbf{~ s d}^{\mathbf{a}}$ & RSD\% & RE \% & Certified Value \\
\hline Cl \% & $0.259 \pm 0.015$ & 5.7 & 9.0 & $0.2840 \pm 0.0215$ \\
$\mathbf{K} \%$ & $1.747 \pm 0.081$ & 4.6 & 8.5 & $1.91 \pm 0.12$ \\
$\mathbf{M g} \%$ & $0.276 \pm 0.041$ & 15 & 5.7 & $0.292 \pm 0.018$ \\
$\mathbf{M n ~} \mathbf{~ \% g} / \mathbf{k g}$ & $178.9 \pm 7.5$ & 4.2 & 6.3 & $191 \pm 12$ \\
$\mathbf{~ N a ~ \% ~}$ & $0.0359 \pm 0.0019$ & 5.3 & - & $(0.0350)^{\mathrm{b}}$ \\
\hline
\end{tabular}

${ }^{a}$ : mean and standard deviation of 2 individual determinations; ${ }^{b}$ :informative value

\subsection{Results of essential elements in edible seaweeds}

Table 3 shows mean results for the essential elements in seaweeds obtained for duplicate determinations. All results presented are related to the dry weight (dw) of the samples as can be verified in Table 3. 
Table 3: Concentrations of the elements in the samples of seaweeds

\begin{tabular}{|c|c|c|c|c|c|c|c|}
\hline \multirow{3}{*}{ Species } & \multirow{3}{*}{ Origin } & \multicolumn{5}{|c|}{ Mean $\pm \mathbf{S D}^{\mathrm{a}}$} & \multirow{3}{*}{$\begin{array}{l}\mathrm{Na} / \mathrm{K} \\
\text { ratio }\end{array}$} \\
\hline & & \multirow{2}{*}{$\begin{array}{c}\mu \mathrm{g} / \mathrm{kg} \\
\mathrm{Mn}\end{array}$} & \multicolumn{4}{|c|}{$\%$} & \\
\hline & & & Cl & $\mathbf{K}$ & Mg & $\mathrm{Na}$ & \\
\hline \multirow{4}{*}{$\begin{array}{c}\text { Porphyra } \\
\text { umbilicates } \\
\text { (Nori) }\end{array}$} & China & $26.8 \pm 1.6$ & $0.687 \pm 0.048$ & $1.445 \pm 0.018$ & $0.356 \pm 0.019$ & $0.872 \pm 0.042$ & 0.603 \\
\hline & Korea & $34.5 \pm 3.0$ & $0.518 \pm 0.009$ & $1.56 \pm 0.14$ & $0.277 \pm 0.011$ & $0.685 \pm 0.069$ & 0.439 \\
\hline & Japan & $13.3 \pm 0.7$ & $1.181 \pm 0.082$ & $2.5 \pm 0.1$ & $0.312 \pm 0.024$ & $0.45 \pm 0.03$ & 0.18 \\
\hline & USA & $33.2 \pm 2.3$ & $0.951 \pm 0.056$ & $1.86 \pm 0.17$ & $0.369 \pm 0.017$ & $0.765 \pm 0.047$ & 0.411 \\
\hline \multirow{3}{*}{$\begin{array}{c}\text { Hijikia fusi- } \\
\text { forme } \\
\text { (Hijiki) }\end{array}$} & Japan & $21.3 \pm 1.6$ & $0.823 \pm 0.069$ & $3.53 \pm 0.20$ & $0.684 \pm 0.064$ & $0.918 \pm 0.079$ & 0.260 \\
\hline & China & $23.8 \pm 2.1$ & $1.88 \pm 0.20$ & $1.31 \pm 0.14$ & $0.604 \pm 0.079$ & $1.29 \pm 0.10$ & 0.984 \\
\hline & Korea & $20.3 \pm 2$ & $0.565 \pm 0.055$ & $3.93 \pm 0.14$ & $0.49 \pm 0.06$ & $1.04 \pm 0.14$ & 0.264 \\
\hline \multirow{3}{*}{$\begin{array}{l}\text { Undaria pin- } \\
\text { natifida } \\
\text { (Wakame) }\end{array}$} & China & $13.9 \pm 1.7$ & & $0.481 \pm 0.053$ & $0.403 \pm 0.04$ & $8.84 \pm 0.85$ & 18.37 \\
\hline & Korea & $13.2 \pm 1.7$ & $\mathrm{~b}$ & $0.285 \pm 0.007$ & $0.818 \pm 0.075$ & $7.03 \pm 0.51$ & 24.6 \\
\hline & China & $28.7 \pm 0.3$ & & $0.331 \pm 0.007$ & $0.905 \pm 0.069$ & $7.30 \pm 0.39$ & 22.05 \\
\hline \multirow{3}{*}{$\begin{array}{c}\text { Laminaria sp } \\
\text { (Kombu) }\end{array}$} & Korea & $2.4 \pm 0.3$ & $9.52 \pm 0.45$ & $9.25 \pm 0.93$ & $0.536 \pm 0.33$ & $2.54 \pm 0.18$ & 0.274 \\
\hline & Japan & $4.9 \pm 0.3$ & $10.6 \pm 1.1$ & $8.3 \pm 0.48$ & $0.90 \pm 0.12$ & $3.37 \pm 0.38$ & 0.406 \\
\hline & China & $2.2 \pm 0.6$ & $6.61 \pm 0.06$ & $11.7 \pm 9.16$ & $0.33 \pm 0.32$ & $2.13 \pm 0.19$ & 0.18 \\
\hline
\end{tabular}

${ }^{\mathrm{a}}$ : Mean and standard deviation for 2 determinations, ${ }^{\mathrm{b}}:$ not determined

The element concentrations in seaweeds are strongly dependent on the types of species, maturity and environmental conditions [4].

In this study large variability can be observed among the seaweed species in relation to their $\mathrm{Cl}$, $\mathrm{K}, \mathrm{Mg}, \mathrm{Mn}$ and $\mathrm{Na}$ contents. The larger variability was found for $\mathrm{Mn}$ in the Porphyra umbilicates species from different countries.

However Hijikia fusiforme, Undaria Pinnatifida and Laminaria sp species collected from different countries showed similar levels of the $\mathrm{Mg}, \mathrm{Mn}, \mathrm{Na}$ and $\mathrm{Cl}$ content of the seaweeds ranged 
from $0.518 \%$ dry weight in species Porphyra umbilicates (Nori-Korea) to $1.181 \% \mathrm{dw}$ in Porphyra umbilicates (Nori-Japan). Hou and Yan (1998) observed that $\mathrm{Cl}$ concentrations in seaweeds are also highly variable and for the same species of algae. However it was not observed in the analyzed samples.

The Porphyra umbilicates samples presented the highest Mn concentrations ranging from 13.3 to $33.2 \mathrm{mg} / \mathrm{kg} \mathrm{dw}$. $\mathrm{Mg}$ concentrations in seaweeds did not vary over a wide range $(0.28$ to $0.91 \mathrm{mg} / \mathrm{kg} \mathrm{dw})$.

The highest Na concentration was observed in the Undaria pinnatifida (7.03- $8.84 \%)$. It is about 10 times higher than that Porphyra umbilicates ( 0.45 to $0.872 \%$ dw) and Hijikia fusiforme (0.918 to $1.29 \%$ dw). Similar result was obtained by Dawczynski et al (2007). In contrast Undaria pinnatifida showed the lowest K concentrations.

According to Dawczynski et al. (2007) the consumption of food with a high $\mathrm{Na} / \mathrm{K}$ ratio quotient may cause high blood pressure as $\mathrm{n}$ in experimental rats. In this study the $\mathrm{Na} / \mathrm{K}$ ratio are low, about 0.30 to Porphyra umbilicates. Hijikia fusiforme and Laminaria sp. On the other hand the $\mathrm{Na} / \mathrm{K}$ ratio was high to Undaria pinnatifida, circa of the 20 times the other analyzed seaweeds.

\section{CONCLUSION}

INAA proved to be useful to determine essential elements in seaweeds. The analyzed species showed to be safe due to their low $\mathrm{Na} / \mathrm{K}$ ratios, except for Undaria pinnatifida. For this species, consumption should be moderate.

\section{ACKNOWLEDGMENT}

The authors would like to thank the Nuclear and Energy Research Institute (IPEN - CNEN/SP) and the CNPq for the fellowship. 


\section{REFERENCES}

[1] VIDOTTI, E. C.; ROLLEMBERG, M. C. E. Algas: da economia nos ambientes aquáticos à bioremediação e à química analítica. Quím. Nova, v. 27, p. 139-145, 2004.

[2] DAWCZYNSKI, C.; SCHÄFER, U.; LEITERER, M.; JAHREIS, G. Nutritional and Toxicological importance of macro, trace, and ultra-trace elements in algae food products. J Agricul Food Chem, v .55, p. 10470-10475, 2007.

[3] DE LA ROCHA, S. R.; SÁNCHEZ-MUNIZ, F. J.; GÓMEZ-JUARISTI, M.; MARÍN, M. T. L. Trace elements determination in edible seaweeds by an optimized and validated ICP-MS method. J Food Compos Anal, v. 22, p. 330-336, 2009.

[4] COFRADES, S, I., LÓPEZ-LÓPEZ, L., BRAVO, C., RUIZ-CAPILLAS, S., BASTIDA, M, T., LARREA, F., JUMÉNEZ-COLMENERO. Nutritional and antioxidant properties of different brown and red Spanish edible Seaweeds. Food Sci Technol Int, v.16, p. 361-370, 2010.

[5] JIMÉNEZ-ESCRIGB, A.; SÁNCHEZ-MUNIZ, F. J.; Dietary fiber from edible seaweeds: Chemical structure, physicochemical properties and effects on cholesterol metabolism Nutr Res Rev, v. 20, p. 585-598, 2000.

[6] SHALABY E., Algae as promising organisms for environment and health Plant Signal Behav, v. 6, p. 1338-1350, 2011.

[7] KU, C. K.; YANG, Y., PARK, Y.; LEE, J. Health benefits of blue-green algae: Prevention of cardiovascular disease and nonalcoholic fatty liver disease. J Med Food, v. 16, p. 103-111, 2013. 
[8] GALLAGER, M. L. The nutrients and their metabolism. In: MAHAN, L.K.; ESCOTTSTUMP, S. Krause's Food nutrition therapy, 12 $2^{\text {th }}$ ed., St.Louis: Saunders, 2008.

[9] AVEgliano, R. P.; MAIHARA, V. A.; SILVA, F. F. A. Brazilian total diet study: Evaluation of essential elements. J Food Compost Anal, v. 24, p. 1000-1016, 2011.

[10] HOU, X.; YAN, X.; Study on the concentration and seasonal variation of inorganic elements in 35 species of marine algae. Sci Total Environ, v. 222, p. 141-156, 1998. 